\title{
Informed consent: the intricacies
}

\author{
Should the BMJ reject all studies that do not include informed consent?
}

See p 1071, 1077, 1107, 1111, 1134, 1065,1066
$\mathrm{S}$ hould the $B M J$ reject all studies that do not include informed consent? That's a simple question, and surely the answer should be equally simple- "Yes." Unfortunately, ethical questions rarely allow simple answers, and we want help with answering this one. This issue includes a cluster of material that relates to the question. We publish the materialincluding two studies in which informed consent was not sought-to encourage debate and to arrive at a deeper understanding if not a simple answer.

Medical journals must consider the ethical aspects of all the material they publish, and medical editors are presented with ethical issues just as often as doctors - that is, every day. Almost everything that doctors and editors do has an ethical aspect. However, a paper published last month in JAMA shows that many journals do not give their authors clear ethical guidance. ${ }^{1}$ A survey of the published instructions to authors of the 102 major English language biomedical journals showed that a quarter did not give authors any guidance on human research ethics, and only half required approval by an ethics committee or institutional review board before publication.

An accompanying editorial looked at 53 consecutive research papers published in Annals of Internal Medicine, BMJ, Lancet, JAMA, and New England Journal of Medicine. ${ }^{2}$ The authors found that $47 \%$ did not record informed consent and 58\% did not record approval by an ethics committee or institutional review board. Importantly, they found six papers in which they judged there was a compelling need for informed consent or approval by an ethics committee or institutional review board and yet where there was no mention of either. These data are supported by a study that found that, of 586 interventional studies published in four geriatrics journals, only 54\% included informed consent and $40 \%$ included approval by an ethics committee or institutional review board. ${ }^{3}$ The JAMA editorial recommends that journals explicitly ask authors to state that their research complies with the World Medical Association's Declaration of Helsinki. ${ }^{2}$

The Declaration of Helsinki includes four paragraphs specifically on informed consent and does allow physicians sometimes to do without informed consent in the context of "medical research combined with professional care (clinical research)." The first paragraph states: "In any research on human beings, each potential subject must be adequately informed of the aims, methods, anticipated benefits and potential hazards of the study and the discomfort it may entail.
He or she should be informed that he or she is at liberty to abstain from participation in the study and that he or she is free to withdraw his or her consent to participation at any time. The physician should then obtain the subject's freely given informed consent, preferably in writing." The next two paragraphs consider patients in a dependent relationship with physicians or who are not legally competent. The "let out" paragraph says: "If the physician considers it essential not to obtain informed consent, the specific reasons for this proposal should be stated in the experimental protocol for transmission to the independent committee."

Both the studies that we publish comply with the Declaration of Helsinki. Both were approved by ethics committees. Those committees agonised over the studies, and both papers include a detailed account of why the researchers did not obtain fully informed consent. But should the $B M J$ set a higher-or at least more explicit-standard than the Declaration of Helsinki?

One of the studies, from Edinburgh, is a randomised controlled trial of whether stroke family care workers improve outcomes for patients with stroke and their families (p 1071). ${ }^{5}$ The authors decided against seeking consent for randomisation primarily on the grounds that a detailed knowledge of the trial and its exact purpose would bias outcomes, which were essentially subjective. In addition, they did not expect the intervention to be harmful, and patients and their families could decline to see the stroke family care worker (p 1077). ${ }^{6}$ Sheila McLean, a professor of law and ethics in medicine, argues that their reasons are insufficient to justify deviation from the general rule that good research must at all times respect the subject (p 1076). " "Any failure," she writes, "to offer this respect is in itself a harm, even if its consequences are not physical."

The second study, from South Africa, was a prospective double blind study of whether infection with HIV affected the outcome of patients admitted to an intensive care unit (p 1077). ${ }^{8}$ This is an important question because when resources are tight there is a tendency not to admit patients infected with HIV to intensive care units. Patients did not give consent to be in the study or to have their blood tested for HIV. The authors argue that consent could not be obtained from most cases because they were too sick and that the research was of such importance that the patients' right to informed consent could be waived (p 1082). ${ }^{9}$ The chairman of the ethics committee explains why the 
committee supported the research after its immediate reaction that it would not be possible to give ethical approval (p 1083). ${ }^{10}$ The explanations include the facts that the study entailed no interventions of any sort different from those that are necessary and are carried out in standard intensive care and that the injury done to the patients would be small. Rajendra Kale, an Indian neurologist, argues that the ethics committee was wrong to approve the research and that the $B M J$ is wrong to publish it (p 1081). ${ }^{11}$ He thinks that such research would not have been allowed in a fully developed country and worries that it may be too easy to flout fundamental human rights in the developing world.

The editors of the $B M J$ and our reviewers were divided on whether we should publish these papers. In the end we decided-and I as editor must accept full responsibility-that, rather than restrict the debate to ourselves, we would do better to invite our readers to join in. We are thus publishing the papers together with their commentaries and with an argument from Len Doyal, a professor of medical ethics, that the $B M J$ should not in future publish papers like these (p 1107). ${ }^{12}$ He proposes a policy that all medical journals might follow.

Professor Doyal writes that "Our abilities to deliberate, to choose, and to plan for the future are the focus of dignity and respect which we associate with being an autonomous person capable of participation in civic life." To deny patients participating in research full information on that research is, he argues, a clear breach of their moral rights. Professor Doyal then examines the arguments against fully informed consent: patients may be distressed by detailed information; it may not be necessary when the risks of the research are negligible; and the interests of the public in medical progress will be undermined by too much emphasis on the rights of individual patients. He finds all these arguments unconvincing.

But he does identify three sets of circumstances in which informed consent may not be necessary. So long as a set of conditions are met then research may be allowed without consent on patients not competent to give consent-including children, patients with learning difficulties, and unconscious or semiconscious patients. Otherwise, such patients will be denied the benefits of research. Secondly, epidemiological research on medical records may be acceptable in certain strict circumstances when, for practical reasons, consent cannot be obtained. Thirdly, research without informed consent may sometimes be acceptable on stored tissue from anonymous donors.

Jeffrey Tobias, a radiotherapist argues that the $B M J$ is right sometimes to publish studies where patients have not given informed consent ( $p$ 1111). ${ }^{13}$ His argument revolves around the facts that patients trust their doctors and that what is clear in "fine and lofty places" like the letters pages of medical journals is much less clear in the "real world," where "the doctor must somehow juggle the multiple responsibilities of expert, humane, and above all respectful support for the patient ... with the wider healthcare concerns and requirements of society as a whole."

The patient's voice is heard in this debate from an anonymous patient who was included in 1987 in a British trial of a new radiotherapy protocol for cervical cancer without being asked for fully informed consent (p1134). ${ }^{14}$ She suffered severe consequences from the treatment and later discovered that she was one of many patients who had been included in trials without consent. She feels abused and quotes another patient who wrote: "Somewhere, somehow, I have to expose this abuse of power. The doctors never got my informed consent. This is abuse of society's most vulnerable people. Where is there a platform for my voice to be heard, to make the public aware and the establishment accountable?" Our anonymous patient is against the $B M J$ publishing any trials that do not include informed consent.

Also in this issue, a news report from India describes how the Indian Council of Medical Research approved research that, without written informed consent, left women with precancerous uterine cervical lesions without treatment to study the natural course of the condition (p 1065). ${ }^{15}$ And a second news report describes how the Council of Europe is developing a legally binding set of rules on bioethics. These stipulate that research can be carried out only if subjects have given informed consent ( $p$ 1066). ${ }^{16}$ The rules do not have a "let out" clause to waive informed consent in people able to give consent, but they do allow research without consent in some circumstances in those who do not have the capacity to consent.

These are not easy issues, but we cannot avoid them. Researchers are likely to continue to want to do trials that do not include fully informed consent, ethics committees will be asked for their opinion, and medical journals will be offered the results to publish. The Declaration of Helsinki does not provide sufficient guidance, and the BMJ needs your help. Should we adopt the policy proposed by Professor Doyal or a version of it? Or should we continue sometimes to publish papers that do not include consent?

Richard Smith

Editor

$B M J$,

London WC1H 9JR

1 Amdur RJ, Biddle C. Institutional review board approval and publication of human research results. JAMA 1997;277:909-14.

2 Rennie D, Yank V. Disclosure to the reader of institutional review board approval and informed consent. JAMA 1997;277:922-3.

3 Rikkert M, ten Have H, Hoefnagels W. Informed consent in biomedical studies on aging: survey of four medical journals. BMJ 1996;313:1117-20. 4 Declaration of Helsinki. BMJ 1996;313:1448-9.

5 Dennis M, O'Rourke S, Slattery J, Staniforth T, Warlow C. Evaluation of a stroke family care worker: results of a randomised controlled trial. BMJ 1997;314:1071-6.

6 Dennis M, O'Rourke S, Slattery J, Staniforth T, Warlow C. Commentary: evaluation of a stroke family care worker: why we didn't ask patients for their consent to be randomised. BMJ 1997;314:1077.

7 McLean S. Commentary: not seeking consent means not treating the patient with respect. BMJ 1997;314:1076.

8 Bhagwanjee S, Muckart D, Jenna PM, Moodley P. HIV status does not influence outcomes of patients admitted to a surgical intensive care unit. BMJ 1997;314:1077-81.

9 Bhagwanjee S, Muckart D, Jenna PM, Moodley P. Commentary: why we did not seek informed consent before testing patients for HIV. BMJ 1997;314:1082-3.

10 Seedat YK. Commentary: no simple and absolute ethical rule exists for every conceivable situation. BMJ 1997;314:1083-4.

11 Kale R. Commentary: failing to seek patients' consent to research is always wrong. BMJ 1997;314:1081-2.

12 Doyal L. Journals should not publish research to which patients have not given fully informed research-with three exceptions. BMJ 1997;314: 1107-11.

13 Tobias JS. $B M /$ s s present policy (sometimes approving research in which patients have not given fully informed consent) is wholly correct. $B M J$ 1997;314:1111-4.

14 All treatments and trials must have informed consent. BMJ 1997;314:1134-5.

15 Mudur G. Indian study of women with cervical lesions called unethical. BMJ 1997;314:1065.

16 Watson R. European bioethics convention signed. BMJ 1997;314:1066. 


\title{
Spacer devices in the treatment of asthma
}

\author{
Amount of drug delivered to the patient can vary greatly
}

$\mathrm{S}$ pacer devices are becoming increasingly popular for the delivery of inhaled drugs in the treatment of asthma. They reduce the problems of poor inhaler technique with metered dose inhalers, largely eliminate oral absorption of inhaled corticosteroids, ${ }^{1}$ and have been shown to be as effective as nebulisers in the treatment of acute severe asthma. By the attachment of facemasks they can be adapted to treat patients of all ages. ${ }^{2}$ Their popularity has led to a rapid increase in the number of different types of spacer available.

As with other inhalation devices, such as nebulisers, the proportion of the dose of the drug that the patient actually inhales may vary greatly with different spacers. Despite the apparent simplicity of the designs, spacer choice and method of use may dramatically alter the amount of drug available for inhalation. Recent laboratory studies, ${ }^{3-7}$ supported by emerging pharmacokinetic evidence and radiolabelled deposition studies, ${ }^{8-10}$ demonstrate where the incorrect use of a spacer can affect the amount of drug delivered.

Multiple actuations of the metered dose inhaler into the spacer before inhalation may reduce the proportion of the drug inhaled. ${ }^{3-6}$ Five actuations of a corticosteroid inhaler into a large volume spacer before inhalation will deliver a similar dose as if a single dose had been actuated into the same spacer and inhaled immediately. ${ }^{5}$ Several clinical studies have used multiple actuations into the spacer before inhalation, ${ }^{11}{ }^{12}$ which may affect their interpretation.

In one study in which inhaled corticosteroids were given via a spacer the theoretical dose administered enabled patients to be weaned off oral steroids. ${ }^{11}$ Multiple actuations of drug into the spacer were used (personal communication). If a similar nominal dose is given as a series of single actuations before a series of inhalations, a considerably larger dose will be achieved. Another example is a dose equivalence study between salmeterol and salbutamol. ${ }^{11}$ This concluded that salmeterol was 10 times more potent, but the salbutamol metered dose inhaler was actuated five times into a large volume spacer before inhalation, reducing the amount of salbutamol available to the patient by about $60 \%$ compared with five single actuations followed by inhalation. ${ }^{6}$ Thus, the true potency of salmeterol may be nearer to four times that of salbutamol.

Delay between putting the metered dose into the spacer and inhalation may also reduce the amount of drug available to the patient. ${ }^{3-6}$ Spacers reduce the need for patients to coordinate inhalation with actuation of the metered dose inhaler, but to maximise the drug delivery period, inhalation should start as soon as possible after actuation of the inhaler. If a health professional or a carer is actuating the inhaler for the patient this should be done only when the patient is ready and the spacer in place.

Static electricity accumulates on many polycarbonate and plastic spacers, attracting drug particles, which become charged when they are produced by the metered dose inhaler. Highly charged spacers deliver less drug than those with an antistatic lining. ${ }^{43} \mathrm{~A}$ simple way of reducing any charge on a spacer is to wash it, ${ }^{14}$ which has a similar effect on drug delivery as antistatic paint, ${ }^{48}$ but the charge may reaccumulate. Spacers made of antistatic materials or metals may reduce this problem. $^{15}$ If a patient or general practitioner carries a new plastic spacer for occasional use, it should be regularly washed to reduce the charge.

Spacer size may also affect the amount of drug available for inhalation, but this will vary with the drug prescribed. ${ }^{16}{ }^{17}$ Preparations differ in the speed and volume of their aerosol cloud, ${ }^{18}$ and this may alter the amount of drug delivered from different spacers. For example, a recent laboratory study showed that the amount of sodium cromoglycate recovered in particles smaller than $5 \mu \mathrm{m}$ in diameter from the Fisonair, a large volume spacer, was $118 \%$ of that recovered when the standard metered dose inhaler was used alone. ${ }^{19}$ The dose recovered from smaller volume spacers was a third of that from the metered dose inhaler alone. These large differences between spacers were not found in tests using budesonide: the amount of the drug recovered in small particles from large and small spacers was similar. Doctors should be aware that data about a spacer derived from studies with one drug may not apply to other drugs. Changing from one spacer to another may be unimportant with some drugs but be critical for others. The size of the spacer may be less important in young children, in whom breathing pattern has an important effect on the dose of drug received. ${ }^{7} 17$

Newer formulations in which hydrofluoroalkanes have replaced older propellents may behave very differently in spacers. In one study the amount of drug delivered by a new salbutamol preparation via a spacer device was double that from a conventional metered dose inhaler delivered via the same spacer. ${ }^{20}$

Much of the available information about spacers has come from laboratory studies in which the drug was collected on filters or in particle sizing apparatus. Recent pharmacokinetic studies have supported the laboratory findings. Maximizing drug output from spacers may improve therapeutic responses and reduce costs. Despite the recent increase in the popularity and number of spacers, little information is available (and little is demanded by regulatory authorities) on the amount of drug available for inhalation from various spacers.

What advice can be given in the light of currently available evidence? Introduce the drug into the spacer by repeated single actuations of the metered dose inhaler, each followed by inhalation. Keep delay to a minimum between actuation of the inhaler and inhalation from the spacer. In certain spacers reduce any static charge by washing and drying in air before first use. Finally, the choice of a spacer must take compliance 
into account. The first choice on scientific grounds may come second to the one that the patient prefers.

Christopher O'Callaghan

Senior lecturer

Peter Barry

Lecturer

Department of Child Health,

University of Leicester,

Leicester LE2 7LX

1 Selroos $\mathrm{O}$, Halme M. The effect of a Volumatic spacer and mouth rinsing on systemic absorption of inhaled corticosteroids from a metered dose inhaler and dry powder inhaler. Thorax 1991;46:891-4.

2 O'Callaghan C, Milner AD, Swarbrick A. Spacer device with facemask attachment for giving bronchodilators to infants with asthma. BMJ 1989;298:160-1.

3 Barry PW, Robertson C, O'Callaghan C. Optimum use of a spacer device. Arch Dis Child 1993;69:693-4.

4 Barry PW, O'Callaghan C. The effect of delay, multiple actuations and spacer charge on the in vitro delivery of budesonide from the Nebuhaler. BrJ Clin Pharmacol 1995;40:76-8.

5 O'Callaghan C, Cant M, Robertson C. Delivery of beclomethasone diproprionate from a spacer device: what dose is available for inhalation? Thorax 1994;49:961-4.

6 Barry PW, O'Callaghan C. Multiple actuations of salbutamol metered dose inhaler into a spacer device reduce the amount of drug recovered in the respirable range. Eur Respir J 1994;7:1707-9.

7 Everard ML, Clark AR, Milner AD. Drug delivery from holding chambers with attached facemask. Arch Dis Child 1992;67:580-5.

8 Clarke DJ, Lipworth BJ. Lung bioavailability of salbutamol from a spacer device comparing single versus multiple actuations, delayed inha- lation and antistatic treated spacer [abstract]. Thorax 1995;50(suppl 2):A79.

9 Hindle M, Chrystyn H. Relative bioavailability of salbutamol to the lung following inhalation using metered dose inhalation methods and spacer devices. Thorax 1994;49:549-53.

10 Kenyon CJ, Thorrson L, Borgstrom L, Newman SP. Reduction in lung deposition of budesonide pressurised aerosol resulting from static charge in plastic spacer devices. In: Drug delivery to the lungs VII. Bristol: The Aerosol Society,1996:17-8.

11 Smyth ET, Pavord ID, Wong CS, Wisniewski AFZ, Williams J, Tattersfield AE. Interaction and dose equivalence of salbutamol and salmeterol in patients with asthma. BMJ 1993;306:543-5.

12 Hummel S, Lehtonen L. Comparison of oral-steroid sparing by high-dose and low-dose inhaled steroid in maintenance treatment of severe asthma. Lancet 1992;340:1483-7.

13 O'Callaghan C, Lynch J, Cant M, Robertson C. Improvement in drug delivery from spacer devices by use of an antistatic lining. Thorax 1993;48:603-6.

14 Wildhaber JH, Devadason SG, Eber E, Hayden J, Everard ML, Summers $\mathrm{QA}$, et al. Effect of electrostatic charge, flow, decay and multiple actuations in the in vitro delivery of salbutamol from different small volume spacers for infants. Thorax 1996;51:985-8.

15 Bisgaard H, Anhøj J, Klug B, Berg E. A non-electrostatic spacer for aerosol delivery. Arch Dis Child 1995;73:226-30.

16 Barry PW, O'Callaghan C. The optimum size and shape of spacer devices for inhalational therapy. J Aerosols Med 1995;8:303-5.

17 Agertoft L, Pedersen S. Influence of spacer device on drug delivery to young children with asthma. Arch Dis Child 1994;71:217-9.

18 Barry PW, O'Callaghan C. Video analysis of the aerosol cloud produced by metered dose inhalers. Pharm Sci 1995;1:119-21.

19 Barry PW, O'Callaghan C. Inhalational drug delivery from seven different spacer devices. Thorax 1996;51:835-40.

20 Barry PW, O'Callaghan C. The use of the chlorofluorocarbon free salbutamol preparation, Airomir, with different spacer devices. Eur Respir $J$ (in press).

\section{Back pain, pregnancy, and childbirth}

\section{Postpartum pain is most likely to be a continuation of antepartum pain}

$\mathrm{B}$ ackache is a common symptom in women of childbearing age. With as many as half of women reporting back pain at some stage during pregnancy, ${ }^{1-3}$ it is perhaps not surprising that many of their carers dismiss it as unimportant. But backache in pregnancy is a substantial problem. Many women are helped by understanding the likely cause of the pain and by advice on prevention and management.

There seems to be little difference in the prevalence of backache between pregnant and non-pregnant women. ${ }^{3}{ }^{4}$ Of Swedish women questioned between the ages of 38 and 64, two thirds reported experiencing back pain at some time, and only a minority said that it had started in pregnancy. ${ }^{3}$ However, backache experienced during pregnancy is more severe and disabling and present for a greater proportion of the time. ${ }^{1}$ About $10 \%$ of women may be prevented by it from working, ${ }^{2}$ and over a third report that it interferes with daily life. ${ }^{3}$

Though non-specific low back pain (radiating classically to buttocks and thighs) is experienced by both pregnant and non-pregnant women, more severe pain arising from sacroiliac dysfunction is particular to pregnancy. It increases in prevalence with gestation concentrations and is often associated with symphyseal pain. ${ }^{2}$ Relaxin, a polypeptide hormone that regulates collagen, softens the ligaments in preparation for parturition. Women with severe pelvic girdle pain in pregnancy have significantly higher serum levels of relaxin than those who are pain free, suggesting that increased joint laxity may be a causative factor. ${ }^{5}$ Other associated factors are a history of backache ${ }^{6}$ (in a sense a self fulfilling prophecy), parity, ${ }^{134}$ physically strenuous and unrewarding employment, ${ }^{23}$ and, paradoxically, younger age. $^{36}$

While ligamentous laxity and extra mechanical stress $^{57}$ would seem ample reason for women to experience severe back pain in pregnancy, other causes may be present. Though lumbar discs rarely prolapse de novo during pregnancy, pregnancy may exacerbate a pre-existing condition and seems to be a risk factor for postpartum disc prolapse. ${ }^{1}$ Joint laxity may also predispose to spondylolisthesis.

The management of backache is not a glamorous aspect of medicine, yet it has attracted attention recently, not least in the $B M J,{ }^{8}$ because of growing evidence that previous strategies such as bedrest, corsets, traction, and physical treatment were valueless. Prevention may be easier than cure for pregnant women and mothers, to whom general advice on back care would seem to be eminently applicable. Take care not to trip, stumble, or move jerkily; bend at the hip and knee rather than stooping forward; avoid twisting the back; do not lift at arm's length; and carry a single load symmetrically in front, on the back, or on the head (would that Western women learnt this art).

If backache occurs, normal activity should be maintained as far as possible. For analgesia, paracetamol is preferred. Specific treatments advocated for sacroiliac joint dysfunction include a trochanteric belt (a form of support for the pelvic girdle) and manipulation, ${ }^{2}$ which produces immediate relief that may not, however, be maintained. 
Signs suggestive of nerve root compression-motor, sensory, or reflex changes of root distribution, or, more seriously, sphincter disturbance with sacral anaesthesia suggesting involvement of the cauda equina-merit urgent referral. As conservative management is preferable to surgery during pregnancy, root pain may be managed with transcutaneous electrical nerve stimulation, while opioid analgesics are best avoided.

For many mothers backache resolves in the first few weeks after delivery, but for some it may continue for months, and for a few it first presents postpartum. Immediately after delievery, up to two thirds of mothers may suffer back pain. ${ }^{10}$ This is sometimes attributed to epidural analgesia in labour. Regrettably, many investigators have failed to distinguish between localised trauma at the site of insertion, which is not uncommon but usually causes transient pain, and generalised backache or sacroiliac strain, which may be reported by $40 \%$ of mothers who do not receive regional analgesia. ${ }^{11}$ Such symptoms may be a continuation of antepartum back pain or may result from excessive straining during the expulsive phase of labour.

Epidural analgesia for labour has been implicated in the development of chronic backache in two retrospective studies. ${ }^{12}{ }^{13}$ It was suggested that mothers receiving epidural analgesia adopted positions stressful to the lower back for prolonged periods and this, combined with muscle weakness and immobility, resulted in postnatal back pain. ${ }^{12}$ However, when this theory was tested in a prospective study, neither motor block nor the use of epidural analgesia was associated with the development of chronic backache. ${ }^{14}$ In both retrospective studies, antenatal backache was reported much less than expected $\left(9 \%\right.$ in one ${ }^{12}$ and $25 \%$ in the other $^{13}$ ), whereas in the prospective investigation $51 \%$ of mothers reported backache during pregnancy. ${ }^{14}$ It would seem that, when questioned months or years after delivery, many women forget that they suffered backache before delivery and instead choose to blame the epidural. Further prospective studies have also failed to demonstrate an association between epidural analgesia in labour and new postpartum backache..$^{15}$ When backache develops postpartum it is rarely severe and usually related to poor posture. ${ }^{13}$

The most likely cause of postnatal back pain is simply that it is a continuation of antenatal problems, ${ }^{14}$ especially since, like antenatal backache, it is more often reported by younger mothers. ${ }^{15}$ In the Swedish survey, pain persisted 18 months after delievery in over a third of the women who had backache during pregnancy. ${ }^{10}$ Chronic postnatal backache was again associated with an increased frequency of previous backache and heavy monotonous work, and more severe discomfort during pregnancy was associated with a longer postnatal course.

Education is again the first step in effective treatment of chronic postnatal back pain. Mothers should be informed about back care and how best to nurse the new baby and can usually be reassured that, with appropriate care and attention to posture, backache should resolve. Oral analgesics may be required, but, should symptoms persist and a chronic pain syndrome develop, long term psychological support may be needed.

It is regrettable that not only women but also many medical practitioners happily refer to "backache following epidural" rather than "backache following childbirth." Given this climate of opinion, postnatal back pain has become a focus of attention and a common cause of litigation. Some women with postpartum backache seem to wish to believe that epidural analgesia has done the damage and reject out of hand any evidence to the contrary. For everyone's peace of mind, women must be reassured that in no prospective study has the use of regional analgesia in labour been associated with an increased risk of chronic backache.

Robin Russell Consultant anaesthetist

John Radcliffe Hospital,

Oxford OX3 9DU

Felicity Reynolds Emeritus professor

Division of Anaesthetics,

St Thomas's Hospital,

London SE1 7EH

1 Fast A, Shapiro D, Ducommun EJ, Friedmann LW, Bouklas T, Floman Y Low back pain in pregnancy. Spine 1987;12:368-71.

2 Berg G, Hammar M, Moller-Nielsen J, Linden U, Thorblad J. Low back pain during pregnancy. Obstet Gynecol 1988;71:71-5.

3 Ostgaard HC, Andersson GBJ, Karlsson K. Prevalence of back pain in pregnancy. Spine 1991;16:549-52.

4 Svensson H-O, Andersson GBJ, Hagstad A, Jansson P-O. The relationship of low back pain to pregnancy and gynecological factors. Spine 1990;15.371-5.

5 MacLennan AH, Nicolson R, Green RC, Bath M. Serum relaxin and pelvic pain of pregnancy. Lancet 1986;ii:243-5.

6 Ostgaard HC, Andersson GBJ. Previous back pain and risk of developing back pain in a future pregnancy. Spine 1991;16:432-6.

7 Ostgaard HC, Andersson GBJ, Schultz AB, Miller JAA. Influence of some biomechanical factors on low back pain in pregnancy. Spine 1993;18:61-5

8 Jayson MIV. ABC of work related disorders: back pain. BMJ 1996;313:355-8

9 Deyo RA. Acute low back pain: a new paradigm for management. $B M J$ 1996;313:1343-4.

10 Ostgaard HC, Andersson GBJ. Postpartum low back pain. Spine 1992;17:53-5.

11 Grove LH. Backache, headache and bladder dysfunction after delivery. $B r$ J Anaesth 1973;45:1147-9.

12 MacArthur C, Lewis M, Knox EG, Crawford JS. Epidural anaesthesia and long term backache after childbirth. BMJ 1990;301:9-12.

13 Russell R, Groves P, Taub N, O'Dowd J, Reynolds F. Assessing long term backache after childbirth. $B M J$ 1993;306:1299-303.

14 Russell R, Dundas R, Reynolds F. Long term backache after childbirth: prospective search for causative factors. BMJ 1996;312:1384-8.

15 Breen TW, Ransil BJ, Groves P, Oriol NE. Factors associated with back pain after childbirth. Anesthesiology 1994;81:29-34.

16 Macarthur A, Macarthur C, Weeks S. Epidural anaesthesia and low back pain after delivery: a prospective cohort study. BMJ 1995;311:1336-9.

\section{Corrections}

\section{Telling patients they have Alzheimer's disease}

An author's error occurred in this editorial by Barnett $S$ Meyers (1 February, pp 321-2). The first reference cited should have read: "Maguire CP, [not Conor PM,] Kirby M, Coen R, Coakley D, Lawlor BA, O’Neill D. Family members' attitudes toward telling the patient with Alzheimer's disease their diagnosis. BMI 1996;313:529-30." Similarly, the authors should have been referred to in the text as "Maguire et al," not Conor et al.

\section{The medical health emergency card}

An error occurred in this editorial by L P Weston and L A Lawson (22 February, pp 532-3). The title of the article should have been "The mental health emergency card."

\section{Disease modifying drugs in rheumatoid arthritis}

An author's error occurred in this editorial by Frank A Wollheim (15 March, pp 766-7). The fourth sentence of the third paragraph should have read: "After five years the radiological assessment of joint damage showed markedly less [not greater] progression in the patients not given disease modifying drugs." 


\title{
Runaway children: whose problem?
}

\author{
A history of running away should be taken seriously: it may indicate abuse
}

$\mathrm{S}$ urprisingly little is known about the extent or importance of running away, particularly in Britain. The police collect the only routine statistics, which are probably an underestimate because of variations in data collection and because parents may not report children who are thought to be safe or who have been abused or thrown out. The total number of reported runaways was 43000 in 1990, a rough incidence of six runaways per 1000 children per year. ${ }^{1}$ By combining the police information with that from a school population study ${ }^{2}$ and projects involving young people living on the streets and in safe houses, ${ }^{3}$ it is possible to distinguish two main groups.

The population survey showed that episodes of running away are quite common. One in seven children aged under 16 say that they have run away overnight, giving a rough incidence of 12 runaways per 1000 children per year. Most are one off episodes, and these children do not go far and generally go alone. They are more likely to come from poor backgrounds and reconstituted families and to have previously played truant from school. However, some of these children are very young ( $11 \%$ were under 11 years), and the fact that half of children running away slept rough suggests that this is not undertaken lightly or for fun. Not enough is known about why these children run away; it may be temporary rebellion, exploration, or unhappiness. Some are not reported missing, and some children establish a pattern of repeating what may be an unpleasant experience, so it is important to consider why a child should do this.

There is some overlap between these cases and children in the second group, who establish a pattern of running from their families as an escape from abuse and rejection. This becomes entrenched if they move into substitute care, particularly if there have been frequent placements. These frequent runaways are overrepresented in the police statistics, in which $30 \%$ of children overall have run away from care (particularly residential).

The sequence seems to be abuse or rejection followed by gradual dissociation from families, schooling, and social support. This detachment seems to be inherent and is probably related to previous experiences as much as being in care, and as such it is difficult to redress. Not all chronic running away is from substitute care, indicating that protecting adolescents living with their families can be difficult. The incidence in Britain resembles that in North America, where high rates of previous abuse, up to $75 \%$, are reported. ${ }^{4}$ In such cases, running away should be considered as a failure of child protection, as these children report years of ill treatment before choosing to escape. ${ }^{5}$

Running away may have positive aspects, especially in escaping abuse, but chronic running can easily drift into homelessness with its associated morbidity and vulnerability. ${ }^{6}$ Access to services becomes difficult, although successful schemes are described. ${ }^{7}$ Not much is known about the health or needs of young homeless people in Britain, but in the United States this group has more physical and mental health problems related to accidents, poor nutrition, untreated infections, drug and alcohol misuse, and sexually transmitted diseases. ${ }^{8}$

The links between childhood abuse, running away, street life, and prostitution in Britain were discussed in a recent report. ${ }^{9}$ The Home Office statistics for offences related to prostitution show an increase in both convictions and cautions for children aged under 16 in 1993 (162 and 664 respectively), and this included the successful prosecution of three 12 year olds. It has to be asked whether prosecuting the children rather than the perpetrators is appropriate.

The true incidence of prostitution in runaway or homeless children (that is, of sexual abuse) is not known. It is not readily disclosed, but recent figures suggest an incidence of up to $20 \%{ }^{3}$ Many of these girls are from residential care and are vulnerable to abuse. During the screening of 210 adolescent girls (mean age 14 years) from residential care in a genitourinary clinic 10 years ago, it was noted that $22 \%$ had engaged in prostitution and $31 \%$ had had two or more sexual partners in the preceding four weeks. ${ }^{10}$

Running away should not be viewed as a normal childhood milestone, and as a means of coping or escape it is not a good option for an abused teenager. There are issues of protection for children at home and also difficulties in meeting the needs of frequent runaways, but is it possible to offer more? Accessible services such as street work projects should help, but there are only 25 refuge places for children aged under 16 in the whole of Britain, all in the voluntary sector. ${ }^{2}$ The Children Act aimed to enable more of this provision, but it has failed so far. A history of running away should be taken seriously and abuse considered if there are several episodes. There is a need to provide more coordinated and effective services to reduce the morbidity for these children. Who should take on this responsibility?

F Lawrenson Community paediatrician

Child Health Department,

Leeds Community and Mental Health Services,

St Mary's Hospital,

Leeds LS12 3QE

1 Abrahams C, Mungall R. Runaways: exploding the myths. London: National Children's Home, 1992.

2 Rees G. Hidden truths. Young people's experience of running away. London: Children's Society, 1993.

3 Stein M, Rees G, Frost N. Running the risk. London: Children's Society, 1994.

4 Stiffman AR. Physical and sexual abuse in runaway youths. Child Abuse Negl 1989;13:417-26.

5 Powers JL, Eckenrode J, Jaklitsch B. Maltreatment among runaway and homeless youth. Child Abuse Negl 1990;14:87-98.

6 Homelessness. Lancet 1989;ii:778-9.

7 Ramsden SS, Nyiri P, Bridgewater J, El-Kabir DJ. A mobile surgery for single homeless people in London. BMJ 1989;298:372-4.

8 Morey MA, Friedman LS. Health care needs of homeless adolescents. Curr Opin Pediatr 1993;5:395-9.

9 Lee M, O'Brien R. The game's up. Redefining child prostitution. London: Children's Society, 1995.

10 Mulcahy FM, Lacey CJ. Sexually transmitted infections in adolescent girls. Genitourin Med 1987;63:119-21. 